\title{
An Evaluation of a Cataract Surgical Camp in New Karu L.G.A., Nasarawa State, Nigeria
}

\author{
Adaora Chinwendu Okudo, Toyin Akanbi \\ Eye Foundation Hospital, Abuja, Nigeria \\ Email: adaoraokudo@gmail.com
}

How to cite this paper: Okudo, A.C. and Akanbi, T. (2022) An Evaluation of a Cataract Surgical Camp in New Karu L.G.A., Nasarawa State, Nigeria. Open Journal of Ophthalmology, 12, 70-76.

https://doi.org/10.4236/ojoph.2022.121008

Received: August 30, 2021

Accepted: February 12, 2022

Published: February 15, 2022

Copyright ( 2022 by author(s) and Scientific Research Publishing Inc. This work is licensed under the Creative Commons Attribution International License (CC BY 4.0).

http://creativecommons.org/licenses/by/4.0/

\section{(c) (i) Open Access}

\begin{abstract}
Aim: To describe the socio-demographic profile of the participants and the ocular pathologies seen during a 3-day free eye screening and cataract surgical camp, to identify the groups we need to create awareness to, and to improve access in subsequent outreaches. Method: A retrospective cross-sectional descriptive study was carried out among 552 participants that attended a cataract surgical outreach camp in New Karu Local Government Area (L.G.A.), Nasarawa State from $10^{\text {th }}$ to $14^{\text {th }}$ September 2013. Data were analyzed using SPSS Version 20 using descriptive analysis such as frequencies and cross-tabulation. $\mathrm{P}<0.05$ was considered statistically significant. Results: Six hundred and sixty-six people registered and 552 were examined comprising of 205 males and 347 females. The majority (81.7\%) were younger than 60 years old, accounting for 4.5 times more than those older than 60 . Females were in the majority (63\%). Amongst those older than 60 years, males were slightly higher as compared to those younger than 60 years, where females were twice as much. Most of the participants (71.3\%) reside within the L.G.A. Amongst those that reside within the L.G.A., females were twice the men and there was a fairly even distribution of both sexes amongst those that reside outside the L.G.A. The majority of the screened participants (41\%) required presbyopic correction. Cataract was the second commonest ocular pathology (22.6\%) and 53 (9.6\%) participants with VA $\leq 6 / 60$ were offered the free cataract surgery. Conclusion: There was an increase in female participation and those younger than 60 years. Amongst those younger than 60 years and those that reside within New Karu L.G.A., female participation was twice as much as males. When the barrier of distance is eliminated, it increases female participation.
\end{abstract}

\section{Keywords}

Evaluation, Cataract, Surgical, Camp, Free, Sociodemographic Factors 


\section{Introduction}

Cataract remains the leading cause of blindness in Nigeria [1]. Cataract surgical coverage in Nigeria was very low as 3/4 of cataract blind eyes had not undergone surgery [2]. Prevalence of cataract blindness in the North Central geopolitical zone was $2.22 \%$, mostly affecting women and the cataract surgical coverage was higher in males $(40.5 \%)$ as compared to $21.8 \%$ of females in the region which shows a barrier to access of cataract surgical coverage mainly amongst women [2]. Various studies have shown that cost and distance to health facilities have been the major barriers to uptake of cataract surgical services [3] [4] [5] [6] [7]. Community eye outreach programmes have played a very important role in improving access to surgeries [8]. A collaboration was then set up between the local Government, a Non-Governmental Organization (NGO) and a community Eye Hospital to run outreaches and free cataract surgeries.

This study aims to describe the sociodemographic profile and the ocular disorders seen amongst those that attended the initial 3 days of surgical outreach and to proffer solutions towards improving subsequent outreach activities, i.e., improving access to those with reduced attendance. This information would help in planning subsequent eye screening and surgical outreach activities in this community by our team, other individuals, groups and the government.

\section{Materials and Methodology}

The study design was a retrospective cross sectional descriptive study. The medical records of all participants who attended the outreach which took place from the $10^{\text {th }}$ to $14^{\text {th }}$ September 2013 were used. Patients who did not wait to be examined or with incomplete records were excluded. The patients were registered at the entry table and their names, age, sex and place of residence, were collected. Their vision was then checked using the Snellen's distant and near chart for both eyes separately with and without a pinhole by 4 trained community health extension workers, then their eyes were examined by 2 ophthalmology residents using a pen torch and direct ophthalmoscope (Keeler). Patients with cataract, whose posterior segment could not be visualized, were counseled for dilatation and consenting patients had their eyes dilated and further posterior segment examination was done using an indirect ophthalmoscope (keeler). Examination findings and diagnosis was recorded in the outreach form.

Glaucoma was defined as a cup-to-disc ratio of $\geq 0.7$ and/or intraocular pressure of $\geq 21 \mathrm{~mm}$ of $\mathrm{Hg}$, with characteristic changes in the optic disc [1].

Refractive error was defined as the presenting visual acuity $\leq 6 / 9$ improving with pinhole [9]. Each eye was tested separately.

Significant cataract was defined using a score of 2 to 3 according to the WHO lens grading system [10].

The variables the study investigated include:

Age: age was grouped into those younger and older 60 years;

Sex: sex was grouped into males and females; 
Place of residence: place of residence was grouped into those that reside within and outside New Karu L.G.A.

Data was collected from the outreach register and screening records and analyzed using descriptive analysis of SPSS 20 statistical software package by the researcher. $\mathrm{P}<0.05$ was considered statistically significant. The study adhered to the tenets of the Declaration of Helsinki. Ethical approval was gotten from the Federal Capital Territory Ethics and Research Committee.

\section{Results}

During the community outreach, 666 people registered and 552 were examined. The response rate was $82.88 \%$. All the 552 subjects examined records were complete and hence used for the analysis.

Of the 552 -subject examined, majority $81.7 \%$ were less than 60 years old accounting for four and a half times more than those above 60 of which females were in the majority $63 \%$.

Amongst those older than 60, males were slightly higher (1.2:1) as compared to those younger than 60 where the female were twice as much. The relationship between the age and sex were found to be statistically significant (Table 1).

Majority of the participants reside within the New Karu L.G. A (71.4\%). All other participants reside within Nasarawa State (Table 2).

Table 1. The gender and age distribution of the screened participants.

\begin{tabular}{cccccc}
\hline \multirow{2}{*}{ Predictor } & & $\begin{array}{c}\text { Age } \\
<60 \text { years }\end{array}$ & $\begin{array}{c}\text { Age } \\
\geq 60 \text { years }\end{array}$ & Total & P value \\
& & $150(73.2 \%)$ & $55(26.8 \%)$ & $205(100.0 \%)$ & \\
Gender & Male & $(33.3 \%)^{*}$ & $(54.5 \%)^{*}$ & $(37.1 \%)^{*}$ & $<0.001$ \\
& & $301(86.7 \%)$ & $46(13.3 \%)$ & $347(100.0 \%)$ & \\
& Female & $(66.7 \%)^{*}$ & $(45.5 \%)^{*}$ & $(62.9 \%)^{*}$ & \\
& & $451(81.7 \%)$ & $101(18.3 \%)$ & $552(100.0 \%)$ & \\
& Total & $(100.0 \%)^{*}$ & $(100.0 \%)^{*}$ & $(100.0 \%)^{*}$ & \\
X2 = 15.880 & & & & & \\
\hline
\end{tabular}

() row percentages; ()$^{*}$ column percentages; Test of significance is the Pearson chi square.

Table 2. The age and residence distribution of screened participants.

\begin{tabular}{lccccc}
\hline \multirow{2}{*}{ Predictor } & & $\begin{array}{c}\text { Age } \\
<60 \text { years }\end{array}$ & $\begin{array}{c}\text { Age } \\
\geq 60 \text { years }\end{array}$ & Total & P value \\
\hline Residence & New Karu L.G. A & $333(84.5 \%)$ & $61(15.5 \%)$ & $394(100.0 \%)$ & 0.007 \\
& Others & $118(74.7 \%)$ & $40(25.3 \%)$ & $158(100.0 \%)$ & \\
& Total & $451(81.7 \%)$ & $101(18.3 \%)$ & $552(100.0 \%)$ & \\
X2 =7.296 & & & & &
\end{tabular}

() row percentages; Test of significance is the Pearson chi square; X2 is the Pearson chi square value. 
Amongst those residents in the L.G.A, females were twice the men and fairly evenly distributed amongst those residing outside (Table 3 ).

Majority (38.6\%) of the screened participants required presbyopic correction and were given. Cataract was the second commonest ocular pathology (21.3\%) (Table 4), although 53 of the 125 cataract patients who had VA $\leq 6 / 60$ were offered the free cataract surgical services.

Table 3. The sex and residence distribution of the screened participants.

\begin{tabular}{lccccc}
\hline \multirow{2}{*}{ Predictor } & & $\begin{array}{c}\text { Sex } \\
\text { Female }\end{array}$ & $\begin{array}{c}\text { Sex } \\
\text { Male }\end{array}$ & Total & P value \\
\hline Residence & New Karu L.G. A & $267(67.8 \%)$ & $127(32.2 \%)$ & $394(100.0 \%)$ & $<0.001$ \\
& Others & $80(50.6 \%)$ & $78(49.4 \%)$ & $158(100.0 \%)$ & \\
& Total & $347(62.9 \%)$ & $205(37.1 \%)$ & $552(100.0 \%)$ & \\
X2 $=14.181$ & & & & & \\
\hline
\end{tabular}

() row percentages; Test of significance is the Pearson chi square; X2 is the Pearson chi square value.

Table 4. Pattern of ocular disorders found amongst screened participants.

\begin{tabular}{cc}
\hline Ocular disorders & Frequency (\%) \\
\hline Presbyopia & $227(38.6 \%)$ \\
Cataract & $125(21.3 \%)$ \\
Allergy & $76(12.9 \%)$ \\
Refractive error & $61(10.4 \%)$ \\
Pterygium & $60(10.2 \%)$ \\
Corneal pathology & $10(1.7 \%)$ \\
Glaucoma & $8(1.4 \%)$ \\
Suspicious disc & $5(0.9 \%)$ \\
Trauma & $5(0.9 \%)$ \\
Maculopathy & $4(0.7 \%)$ \\
Optic atrophy & $4(0.7 \%)$ \\
Infective causes & $2(0.3 \%)$ \\
Squint & $1(0.2 \%)$ \\
Total & $588(100.0 \%)$ \\
\hline
\end{tabular}

() percentages; A patient could have more than one ocular pathology. Seventy-seven people had more than one ocular pathology.

\section{Discussion}

Cataract remains the leading cause of severe visual impairment and blindness responsible for $45.3 \%$ and $43 \%$ respectively in Nigeria [1]. Cataract surgical coverage in Nigeria was very low as $3 / 4$ of cataract blind eyes had not undergone surgery [2]. The prevalence of blindness from the National Blindness Survey is 
$3.75 \%$ for the North Central GPZ [11]. Cataract was found to be the commonest cause of blindness accounting for a prevalence of $2.22 \%$ in the region [1]. In the North Central Geopolitical zone $27.6 \%$ of blind cataract females eyes and $58.3 \%$ of blind cataract males eyes had had surgery (2.1 times higher in males) [2], although cataract blindness has been found to be higher amongst the women [1]. This shows that despite the fact that cataract blindness is higher in females, men have more access to cataract surgical services.

Community eye outreach programmed has played a very important role in improving access to cataract surgical services. These programmes started in the sixties in Asia and Africa and now have extended to other developing countries. High-volume cataract surgeries, drugs, and post-operative follow-up of people with poor access to cataract surgical services have been made possible through these programmes [8].

Based on the situation on ground, a need arose to strengthen the eye care services and meet the unreached and break these barriers. An intersectoral collaboration was then set up between the local Government, an NGO and a community Eye Hospital to run community outreach programmed and free cataract surgeries. The community was involved fully in the planning, creating awareness and implementing the programme in order to ensure community ownership and sustainability of the programme. The aim of the programme was to reduce avoidable blindness in New Karu L.G.A. by taking eye care services nearer to the people in their communities, to screen members of the Local Government Area, to operate those identified to have operable cataract and to treat those with common eye diseases. The screening and surgeries took place in the primary health center in the local government area. Various studies have shown that cost and distance to health facilities have been the major barriers to uptake of cataract surgical services [3] [4] [5] [6] [7], hence the need arose to bring these services to the grass root and to reach the unreached.

As this was the pioneer outreach programme organized by this collaboration, it is important to describe the sociodemographic profile of those that attended the outreach in other to identify the groups that need to be reached out to during subsequent outreaches.

A total of 666 people were found to have registered, of which 552 were examined, which shows that 114 people did not wait to be examined which could be because of long waiting time or they were discouraged because of the crowd. Hence, we have to improve on subsequent outreach camps by reducing waiting time, effective entry and exit table and keeping the people busy by giving health talks, songs and drama through community involvement.

All 552 patients examined had their records complete which showed good planning of patient flow and training of staffs.

Screened participants younger than 60 years were four and a half times more than those older than sixty which could be because in Nigeria the average life expectancy is 49 [12]. Elderly people also tend to have more co morbidities that 
make it difficult for them to leave their homes. Subsequent outreach will need to target more of the elderly as cataract is a disease of age, through involvement of families, age grade meetings, religious groups and community participation.

Females were 1.7 times more than the men. Similar findings by Courtright in Tanzania and Awoyesuku et al. as they were more likely to access services through outreach programmes [3] [13]. Outreach programmes eliminate the barrier of direct cost and transport hence it is more convenient for women to take time from their house chores and because of the short distance they may not require somebody to accompany them to the outreach venue.

Amongst those younger than 60 years, females were twice as much as males while those above 60 , there were slightly more males assessing the outreach. This may be because men younger than 60 had to go to work, hence we can increase their participation by increasing awareness much earlier so they can plan, also extending outreach activities to weekends and much later hours during the day. Similar findings were found in Shenyang, China [14]. Amongst those that reside in New Karu L.G.A. the females were two times more than the men, while those that reside outside were evenly distributed, which buttresses the fact that when the barrier of distance is eliminated females are more likely to attend.

Outreach programmes serve as opportunities for people to have their eyes examined, counseled, receive treatment or appropriate referrals. Majority $38.6 \%$ benefited from presbyopic correction, those with common eye diseases were treated. Cataract was the second highest ocular problem with similar findings in other outreach centers across the country [15]. Fifty three of the 125 cataract patients (42.4) \% with $\mathrm{VA} \leq 6 / 60$ were offered free cataract surgical services.

The strength of the study is that it is a community based descriptive study. The limitation of the study is the data was retrieved from 1 outreach activity and is not generalizable for New Karu L.G.A., Nasarawa State and the study was a retrospective study of which data was collected in 2013.

\section{Conclusion}

There was an increase in female participation and those younger than 60 years. Amongst those younger than 60 years and those that reside within New Karu L.G.A., female participation was twice as much as males. When the barrier of distance is eliminated, it increases female participation.

\section{Conflicts of Interest}

The authors declare no conflicts of interest regarding the publication of this paper.

\section{References}

[1] Abdull, M.M., Sivasubramaniam, S., Murthy, G.V.S., Gilbert, C., Abubakar, T., Ezelum, C. and Rabiu, M.M. (2009) Causes of Blindness and Visual Impairment in Nigeria: The Nigeria National Blindness and Visual Impairment Survey. Investigative Oph- 
thalmology \& Visual Science, 50, 4114-4120. https://doi.org/10.1167/iovs.09-3507

[2] The Nigeria National Blindness and Visual Impairment Survey 2005-2007 Report. http://pbunion.org/Countriessurveyresults/Nigeria/Nigeria survey Summary repo rt.pdf

[3] Lewallen, S. and Courtright, P. (2000) Recognising and Reducing Barriers to Cataract Surgery. Community Eye Health Journal, 13, 20-21.

[4] Fadamiro, C.O. and Ajite, K.O. (2017) Barriers to Utilization of Cataract Surgical Services in Ekiti State, South Western Nigeria. Nigerian Journal of Clinical Practice, 20, 783-786.

[5] Rabiu, M.M. and Muhammed, N. (2008) Rapid Assessment of Cataract Surgical Services in Birnin-Kebbi Local Government Area of Kebbi State, Nigeria. Ophthalmic Epidemiology, 15, 359-365. https://doi.org/10.1080/09286580802399078

[6] Bekibele, C.O. and Murthy, G.V. (2012) Barriers to Cataract Surgery of Persons Screened at Camps in Ibadan, Nigeria. African Journal of Medicine and Medical Sciences, 41, 257-264.

[7] Rabiu, M.M. (2001) Cataract Blindness and Barriers to Uptake of Cataract Surgery in a Rural Community of Northern Nigeria. British Journal of Ophthalmology, 85, 776-780. https://doi.org/10.1136/bjo.85.7.776

[8] Alan, W.J. (1992) The Role of International Non-Governmental Organizations in Dealing with Cataract Blindness in Developing Countries. Documenta Ophthalmologica, 81, 345-348. https://doi.org/10.1007/BF00161772

[9] Opubiri, I. and Pedro-Egbe, C. (2013) Screening for Refractive Error among Primary School Children in Bayelsa State, Nigeria. The Pan African Medical Journal, 14, Article No. 74. https://doi.org/10.11604/pamj.2013.14.74.1345

[10] Thylefors, B., Chylack Jr., L.T., Konayama, K., Sasaki, K., Sperduto, R., Taylor, H.R., et al. (2002) A Simplified Cataract Grading System. Ophthalmic Epidemiology, 9, 83-95. https://doi.org/10.1076/opep.9.2.83.1523

[11] Kyari, F., Gudlavalleb, M.V.S., Sivsubramaniam, S., Gilbert, C.E., Abdull, M.M., Eritekumme, G., Foster, A. and the Nigeria National Blindness and Visual Impairment Study Group (2009) Prevalance of Blindness and Visual Impairment in Nigeria. The national Blindness and Visual Impairment Survey. Investigative Ophthalmology \& Visual Science, 50, 2033-2039. https://doi.org/10.1167/iovs.08-3133

[12] Department for International Development (2018) Final-Statistical Report on Women and Men in Nigeria. https://nigerianstat.gov.ng

[13] Awoyesuku, E.A. and Nathaniel, G.I. (2019) Demographics and Pattern of Referral of Participants at a One-Week Long Free Glaucoma Screening Event. World Journal of Ophthalmology \& Vision Research, 2, Article ID: 000549. https://doi.org/10.33552/WJOVR.2019.02.000549

[14] Cao, Y. (2009) To Evaluate the Screening Camp System of He Eye Hospital and Barriers to Uptake of Cataract Services by the Rural Community, Shenyang, China. Dissertation, the London School of Hygiene and Tropical Medicine, London.

[15] Ogwurike, S. and Pam, V. (2004) Pattern of Eye Diseases in Kaduna State-A Rural Community Outreach Experience. Nigerian Journal of Ophthalmology, 12, 1-5. https://doi.org/10.4314/njo.v12i1.11936 